\title{
The persistence of abnormal returns at industry and firm levels *
}

\author{
Juan Carlos Bou \\ Department of Business Administration and Marketing \\ Universitat Jaume I \\ and \\ Albert Satorra \\ Department of Economics and Business \\ Universitat Pompeu Fabra. Barcelona
}

November 20, 2003

\footnotetext{
${ }^{*}$ The comments by Nick T. Longford on an earlier draft of this paper are very much appreciated. This work has been partially supported by the Spanish Ministry of Science and Technology, Grant BEC 2000-0983, and by the Generalitat Valenciana (Spain), CTESIN/2003/026.
} 
Full Addresses:

Juan Carlos Bou

Department of Business Administration and Marketing

Universitat Jaume I

Avinguda Sos Baynat s/n, 12080 Castelló, Spain Phone: 34-964728537

Fax: 34-964728629

e-mail: bou@emp.uji.es

\author{
Albert Satorra \\ Universitat Pompeu Fabra \\ Department of Economics \\ Ramon Trias Fargas 23, 08005 Barcelona, Spain \\ Phone: $34-935421758$ \\ Fax: 34-935421746 \\ e-mail: satorra@upf.es
}




\begin{abstract}
The present paper proposes a model for the persistence of abnormal returns both at firm and industry levels, when longitudinal data for the profits of firms classified as industries are available. The model produces a twoway variance decomposition of abnormal returns: (a) at firm versus industry levels, and (b) for permanent versus transitory components. This variance decomposition supplies information on the relative importance of the fundamental components of abnormal returns that have been discussed in the literature. The model is applied to a Spanish sample of firms, obtaining results such as: (a) there are significant and permanent differences between profit rates both at industry and firm levels; (b) variation of abnormal returns at firm level is greater than at industry level; and (c) firm and industry levels do not differ significantly regarding rates of convergence of abnormal returns.
\end{abstract}

Keywords: returns of assets, abnormal returns, persistence, two-level structural equations

RUNNING TITLE: Persistence of Abnormal Returns 


\section{INTRODUCTION}

Empirical data shows that, at a given point of time, profit rates differ widely across firms, and also across industries. Some firms earn what can be regarded as high "abnormal returns", whereas other less successful firms earn returns below the mean (Jacobson, 1988). Confronted with this empirical fact, certain basic questions arise. Will firm profit deviations from the equilibrium profit rate disappear over time?; i.e., are these differences merely "transitory"?. If the differences are merely transitory, how quickly will these differences disappear?. If the differences are not merely transitory, i.e. if there is a "permanent" component of profits, how important are these differences compared with the transitory differences between profits?. Furthermore, are profit differences within industries greater than across industries?. With regard to the transitory differences of profits, how fast is convergence to the average profit rate, both within industries and between industries?. Or otherwise, are transitory differences between industries more persistent than between firms ?. These questions are important in industrial organization and strategic management research, and have been addressed in previous studies by many authors.

Two main research directions can be distinguished regarding these questions. In one research line, which we call sources of firm profit differences, the focus is on identifying the level of analysis - whether it be firm, corporation or industry - where differences in profits arise. Previous empirical studies have stressed the importance of the industry, corporation and firm effects into explain profit differences among firms (see Schmalensee, 1985; Rumelt, 1991; Wernerfelt and Montgomery, 1988; Roquebert, Phillips, and Westfall, 1996; Powell, 1996; Mauri and Michaels, 1998; McGahan and Porter, 1997; Brush and Bromiley, 1999). There have been, however, two different perspectives. Classical industrial organization research attributes the existence of profit differences to differences in the structure of the industry, the level where the conduct (strategy) of firms is being shaped (Bain, 1956; Caves, 1980; Porter, 1981); in contrast, strategic management researchers attribute the persistence of abnormal returns to characteristics that operate at firm level (Lippman and Rumelt, 1982; Rumelt, 1984, 1987; Wernerfelt, 1984; Mahoney and Pandian, 1992; Carroll, 1993).

This research on sources of firm profit differences uses cross-section data, variance component analysis (VCA) and nested ANOVA models and assess the relative importance of various sources of firm profit differences. Exceptionally, some authors, such as Rumelt (1991) and Roquebert et al. (1996), also add an industry-year interaction term to their model to capture transient effects at industry level. In the same way, McGahan and Porter (1997, 
1999) allow for serial correlation between error terms to account for transient effects on different levels. The main findings of this line of research can be summarized as follows: (a) there is consensus of opinion regarding the existence of significant firm and industry effects, whereas the relevance of a corporation effect is not yet conclusive (McGahan and Porter, 2002); (b) even though the relative magnitude of firm versus industry effects varies between studies, most of them conclude that the firm effect is greater than the industry effect (see, e.g., Rumelt, 1991; Roquebert et al., 1996; McGahan and Porter, 1997); (c) those who also used time series data reported a significant time dependence on the effects of firm, corporation and industry.

A second line of research, that we call persistence of profits, focuses on the time dependency of profit rates and, specifically, on the convergence process of firm profit differences toward a long-run equilibrium value (e.g. Mueller, 1986, 1990; Odagiri and Yamawaki, 1986; Jacobson, 1988; Geroski 1990; Waring, 1996; McGahan and Porter, 1999; Jacobson and Hansen, 2001). This line of research takes the view that markets are not in equilibrium and that competition is a dynamic process. As opposed to the cross-section (static) view of the research on sources of firm profit differences, the research on profit persistence uses a time-series model perspective to evaluate the evolution of profit-rate differences over time, and tests are performed to find out whether convergence occurs, and whether this convergence is complete (Mueller, 1986). The main findings of this line of research can be summarized as follows: (a) firm profit rates converge towards a mean profit rate (possibly different among the firms); (b) profit differences do not disappear quickly, they persist over time; (c) the process of convergence is not complete to the overall mean (in the long run, no equalization of firm-profit rates is reached). Note that this research line has been based mainly on the analysis of time series data at firm level.

These research directions have been developed separately, using different methodologies and data structures. The present paper proposes a unified treatment for them. We present a model that encompasses the two alternative views of the phenomena of the persistence of abnormal returns. With our approach, we can assess the relative importance of the static and dynamic views of profit rates, as well as the relative contributions of firm and industry to the abnormal return. We specify a dynamic panel two-level model withfirm and industry as its levels -, and apply the standard methodology of SEM (LISREL type) . 


\section{MODEL DEVELOPMENT}

In this paper we use a dynamic model for panel data to examine the issue of the persistence of abnormal returns. This is Anderson and Hsiao's statedependence model (1982), and Kenny and Zautra's trait-state-error model (1985, 2001). The latter we extend to two-level data in a later section. The model decomposes firms' abnormal profits into a static (permanent) component, a dynamic or changing component, and an unexplained or error term component:

$$
\begin{gathered}
Y_{i t}=\lambda_{t} P_{i}+A_{i t}+U_{i t} \\
A_{i t+1}=\beta_{t} A_{i t}+D_{i t},
\end{gathered}
$$

where $Y_{i t}$ denotes the abnormal return of firm $i$ at time $t$ ( $Y_{i t}$ is the difference of the firms' profit in that year minus the overall mean of the firms' profit in that year); $P_{i t}$ is the static or permanent component; $A_{i t}$ represents the autoregressive component; $U_{i t}$ is an idiosyncratic, unexplained, firm-year component; and $D_{i t}$ is the disturbance component of the dynamic autoregressive part of the model. Here $U_{i t}$ and $D_{i t}$ are centered random variables, assumed to be independent across $i$ and $t ; \lambda_{t}$ denotes the factor loading associated with the permanent component, and $\beta_{t}$ is the so-called autoregressive parameter. The component $P_{i t}$ reflects the component of abnormal return that does not change over time, while $A_{i t}$ is the portion of the firm's profitability that varies over time as a first-order autoregressive process, see equation (2). We do not include an intercept term, since we take $Y_{i t}$ to be the firm's profit in deviations from the mean of profits for the given year. In this way we separate industry and firm-specific components from total profitability (Waring, 1996; McGahan and Porter, 1997), thus removing the cyclical component of profitability change (Mueller, 1986).

Figure 1 shows a path diagram representation of the model, as often encountered in SEM. Observable variables are represented in squares, while latent variables are in circles. An arrow leading from the predictor to the dependent variable indicates a "regression" effect. This path diagram shows various latent variables. There is a "permanent" component that exerts a (static) effect on $Y_{i t}$, and a "temporary" component with an autoregressive structure. The absolute value of $\beta$, the first-order autoregressive parameter, indicates the "memory" strength $(\beta=0$, zero memory) of the time dependent component of abnormal returns. In fact, in the model analysed in this paper, the $\lambda_{t}$ 's are set equal to one, though such restriction is not essential (identification is attained by just setting one of the $\lambda_{t}$ 's to a fixed value, usually 1). We will now explain the substantive meaning of the different components appearing in this model in more detail. 
Insert Figure 1 about here

\section{Permanent component, $P_{i}$}

The permanent component represents the stable part of abnormal returns that does not vary over time. It reflects long-run or sustainable differences across firms. Its variance across firms captures profit differences among firms that are not eroded by the competitive process.

As argued in earlier studies (e.g. Mueller, 1986, 1990; Geroski 1990; Waring, 1996; McGahan and Porter, 1997), such a permanent component may include: (a) an industrial-rent component (or industry permanent effect) that is common to all firms in the same industry (i.e., industry-stable structural characteristics due to economies of scale, concentration, entry barriers, product differentiation and so on; see Waring, 1996); (b) a permanent firmspecific rent, or permanent firm-effect, that encompasses many systematic between-firm differences such as due to effectiveness, configuration of activities, organizational processes, managerial competence, resource endowment, product and service quality, first mover advantages, and so on (McGahan and Porter, 1997).

\section{Temporary, or autoregressive component, $A_{i t}$}

The temporary or transient component $\left(A_{i t}\right)$ reflects the part of the firm's profit rate that changes over time. It can be interpreted as short-run rents; ${ }^{1}$ that is, rents that are eroded by the competitive process. Its variance captures differences in the rate of return between firms that disappear over time as a result of the competitive process. The importance of this component depends on the size and frequency (i.e., the innovative propensity of firms; see Roberts, 1999, 2001) of the short-run rents and the extent to which the process of generating these short-run rents is asynchronous across firms (Nesselroade, 1991).

In our model, the temporary component follows a first-order autoregressive process, AR(1). Previous studies (Jacobson, 1988; Mueller, 1986, Geroski and Jacquemin, 1988; Cubbin and Geroski, 1987, 1990; Geroski, 1990, Maruyama and Odagiri, 2002) have shown the first-order autoregressive model to be superior to other alternative specifications (e.g., Mueller's polynomial convergence model (1977), or other higher-order autoregressive

\footnotetext{
${ }^{1}$ McGahan and Porter (1999) refer to this component as the incremental component of the abnormal profits, avoiding the idea that it could last a very long time
} 
processes). This $\mathrm{AR}(1)$ structure implies that short-run rents converge to a mean value (equilibrium rate of return), with the speed depending on the autoregressive parameter $\beta_{t}$; it attains its maximum maximum when $\beta_{t}=0$.

\section{Unexplained firm-year component, $U_{i t}$}

The unexplained component $U_{i t}$ reflects the portion of firm's profit variance that correlates neither across time, nor across firms. It is a "shock" for each year, different for each firm. It encompasses all the specific circumstances that are not stable but affect a firm's profit rate in one specific year. These circumstances can be firm specific (such as extraordinary profits and losses due to breakdowns, damage, and so on) or can affect all firms in the industry (as, for example, an especially poor year due to a general fall in demand). The variation of the variance of $U_{i t}$ along t reflects unequal effects of these circumstances over the years. ${ }^{2}$

The component $U_{i t}$ also encompasses measurement error. Several studies have criticized the use of accounting data to measure economic returns (see, e.g., Demsetz, 1979; Fisher and McGowan, 1983; Benston, 1985). Accounting conventions can introduce substantial errors and bias to the permanent component estimates and to the speed of adjustment (see Mueller, 1990). As noted by McGahan and Porter (1997), we have no a priori hypothesis about the nature and direction of these biases; so, measurement error needs to be introduced as a specific component of firm profitability, as in $U_{i t}$.

\section{Moment structure for the single-level model}

We consider first the model as applied to single-level data (firm level). We show how second-order moments of observable variables can be expressed as a function of the parameters of the model. If the model is identified in terms of such second-order moments (i.e., if two different parameter values correspond to different population second-order moments) then the model can be fitted by SEM-type software. We assume independence among the various sources of variation of abnormal returns (Rumelt, 1991), and a stationary dynamic component of the model. This implies that the autoregressive parameters $\left(\beta_{t}\right)$ are equal across $t$, as well as the variances of the disturbance terms $\left(D_{i t}\right)$ and the loadings $\lambda_{t}$ 's. Since one loading parameter needs to be set a fixed value, all the loadings are set to 1 . This is a more restricted version of the model than it is strictly needed. ${ }^{3}$

\footnotetext{
${ }^{2}$ This component is also called the "state" component in Kenny and Zautra's (2001).

${ }^{3}$ Our modeling starts with a model specification that we found reasonable from the theoretical point of view, and we relax it by freeing some of the restrictions when a
} 
With the above conditions, we obtain ${ }^{4}$

$$
\operatorname{Var}\left(A_{i t}\right)=\operatorname{Var}\left(A_{i t-1}\right) \text {, }
$$

so that

$$
\operatorname{Var}\left(A_{i t}\right)=\frac{\operatorname{Var}\left(D_{i t}\right)}{1-\beta^{2}}
$$

This equality contrains the variance of the transitory component on the first wave, the variance of $A_{i 1}$. It is easy to derive that

$$
\begin{gathered}
\operatorname{Var}\left(Y_{i t}\right)=\lambda^{2} \operatorname{Var}\left(P_{i}\right)+\frac{\operatorname{Var}\left(D_{i t}\right)}{1-\beta^{2}}+\operatorname{Var}\left(U_{i t}\right) \\
\operatorname{Cov}\left(Y_{i t}, Y_{i s}\right)=\lambda_{t} \lambda_{s} \operatorname{Var}\left(P_{i}\right)+\operatorname{Cov}\left(A_{i t}, A_{i s}\right), \quad t \neq s,
\end{gathered}
$$

and

$$
\operatorname{Cov}\left(A_{i t}, A_{i s}\right)=\beta^{|t-s|} \operatorname{Var}\left(A_{i t}\right) .
$$

By the stationary assumption, $|\beta|<1$, the correlation among $A_{i t}$ and $A_{i s}$ decreases to zero when the time distance $|t-s|$ increases. From equations (5) - (7), it can be deduced that different parameters of the model produce different variances and covariances of observed variables, so the model is identified.

\section{The two-level model: firm and industry effects}

This model is now extended to the two-level data, by allowing permanent and temporary differences of firm profit to rise both on firm and industry levels.

We decompose the permanent and temporary component into a firm and industry specific component, recognizing a hierarchical or a two-level structure in the formation of abnormal returns. The model equations are

$$
\begin{aligned}
Y_{i j t} & =y_{I j t}+y_{F i j t} \\
y_{F i j t} & =\lambda_{F t} P_{F i j}+A_{F i j t}+U_{i j t} \\
y_{I j t} & =\lambda_{I t} P_{I j}+A_{I j t} \\
A_{F i(t+1)} & =\beta_{F} A_{F i t}+D_{F i t} \\
A_{I j(t+1)} & =\beta_{I} A_{I j t}+D_{I j t}
\end{aligned}
$$

where $y_{I j t}$ and $y_{F i j t}$ denote the respective industry and firm specific components of observable abnormal return $Y_{i j t}$,

goodness-of-fit test indicates there is needed.

${ }^{4}$ Equality (4) will be used to assign the value of the parameter variance of $A_{i t}$ at the initial condition $t=1, \operatorname{Var} A_{i 1}$. 
$P_{I}$ : is the industry permanent component, or the portion of the permanent component which explains the variance between industries (betweenindustry permanent variability).

$P_{F}:$ is the firm permanent component, or the portion of the permanent component that accounts for the variance within firms.

$A_{I}$ : is the industry temporary component, or the portion of the temporary component at industry level that evolves over time.

$A_{F}$ : is the firm temporary component, or the portion of the temporary component at firm level that evolves over time.

$U$ : is the unexplained error year-firm component that is assumed uncorrelated among years and firms.

$D_{I}$ : is the disturbance variance at industry level.

$D_{F}:$ is the disturbance variance at firm level.

$\beta_{I t}$ : is the industry autoregressive coefficient that can be read as the speed of convergence toward the mean of industry-temporary abnormal returns.

$\beta_{F t}$ : is the autoregressive coefficient at the firm level, that can be read as the speed of convergence toward the mean of industry-temporary abnormal returns.

As in model (1) -(2), both firm and industry temporary components follow a first-order autoregressive process (Waring, 1996; McGahan and Porter, 1997, 1999). We assume independence among permanent, temporary and unique terms, as well as the stationarity of the dynamic component of the model, both at firm and industry levels. The stationarity assumption implies the equality of the autoregressive parameters as well the equality of disturbance terms over time, at industry and at firm levels.

\section{HYPOTHESES}

The decomposition of abnormal firm returns into firm and industry components, as well as permanent versus temporary components, allows us to formulate several hypothesis that have been recognized by literature. 


\section{Convergence of abnormal returns}

Conventional microeconomic theory assumes that, in the long run, abnormal returns disappear because economic forces tend to push them back to the equilibrium level. This corresponds to the belief that there are no systematic (permanent) difference between firms for abnormal returns, and that there is no time dependence among these abnormal returns. This theory sustains that observed differences among abnormal returns are only a transitory phenomenon, due to short-run rents that are eroded instantaneously (or over a shorter term than the time sequence of the observations) by the competitive process. In this case, the evolution of abnormal firm return has the properties of a random shock process ${ }^{5}$. This corresponds to the following simple hypothesis

Hypothesis 0 (HO): Variances of transitory and permanent components vanish both at firm and industry levels (that is, the only significant component of our model is the unexplained firm-year component $U)$.

This hypothesis does not hold if firms' profit rates do not converge completely to the same long-run equilibrium level, or if the process of convergence is not instantaneous. In this case, erected entry (Bain, 1956) or mobility barriers (Caves and Porter, 1977), or the existence of an "isolation mechanism" generated by the strategic behavior of the incumbent firms (Rumelt, 1984), impedes or delays the convergence process.

\section{Persistence of abnormal returns}

The issue of the speed of convergence of abnormal returns to zero, or to some specific value, different for each firm, is referred as in literature as the "persistence" of abnormal returns (Mueller, 1986, 1990; Odagiri and Yamawaki, 1986). The convergence process of abnormal returns is specified as a first-order autoregressive process. ${ }^{6}$

Our model allows for the possibility that H0 does not hold. Several forms of departure from H0 can be distinguished. We can have (a) a significant permanent component of abnormal returns (i.e., a significant variance for the permanent components, at firm or industry levels, or both); (b) some delay in the speed of convergence of abnormal returns; or (c) (a) and (b)

\footnotetext{
${ }^{5}$ Mueller (1986) refers to this hypothesis as the "environmental competitive hypothesis". Geroski (1990) refers to this situation as neoclassical equilibrium.

${ }^{6}$ The autoregressive model is based on the idea that competitive mechanisms need some time to erode the excess of profits generated by short-run rents (Mueller, 1986)
} 
together. These ways of departing from the null hypothesis H0 suggest a new hypotheses that characterizes them.

Hypothesis 1 (H1): The auto-regression coefficient $\beta$ and the variance of the disturbance term of the AR(1) vanish (i.e., the only significant random constituents of the model are the permanent $(P)$ and unexplained components $(U))$

Hypothesis 2 (H2): The variance of the permanent component $P$ vanishes (i.e., the only significant random constituents of the model are the temporary $(A)$ and unexplained components $(U)$ )

Hypothesis 3 (H3): The variances of $P, A$ and $U$ are positive

These hypotheses are summarized in Table 1.

Table 1 about here

\section{Industry versus firm effects}

So far we have only distinguished between permanent and temporary differences of abnormal returns. We have not yet considered the sources, firm or industry, of these differences. Previous empirical variance and covariance analyses (Rumelt, 1991; Roquebert et al., 1996; Mauri and Michaels, 1998; McGahan and Porter, 1997, 1999, 2002) showed that abnormal returns exist both at industry (between industry differences) and firm levels (within industry differences). Although there are differences across studies in the magnitude of the firm and industry effects, the predominant conclusion was that variation at firm level is more important than at industry level. We therefore expect profit differences within industries to be greater than across industries, as stated in the following hypothesis.

Hypothesis 4 (H4): Abnormal returns at firm level are greater than at industry level.

Hypothesis H4 implies that the variance of the firm effect (i.e. the variance of the permanent and temporary firm components) is greater than the variance of the industry effect;

$$
\operatorname{var}\left(P_{F}\right)+\operatorname{var}\left(A_{F}\right)>\operatorname{var}\left(P_{I}\right)+\operatorname{var}\left(A_{I}\right) .
$$




\section{Persistence of industry and firm effects}

The decomposition we attain at industry and firm levels of the temporary and permanent components of abnormal returns allows us to test the differences among firm and industry for the persistence of profit rates. Previous research has established the existence of persistence at industry level (e.g. Coate, 1989, 1991; Waring, 1996; Mueller and Raunig, 1999), and at firm level (e.g. Mueller, 1977, 1986; Odagiri and Yamawaki, 1986; Schwalbach, Grasshoff, and Mahmood, 1989; Roberts, 1999, 2001). A question arises whether convergence of abnormal returns is faster at the firm level than at the industry level. McGahan and Porter (1999) concluded that industry effects are more persistent than firm effects. These results agree with those obtained by Jacobson and Hansen (2001) in their study of the competition process. In our model, the speed of convergence is characterized by the autoregressive coefficient $\beta$. The following hypothesis is thus considered.

Hypothesis 5 (H5): the process of convergence of abnormal returns is faster at industry level than at firm level (that is, at industry level there is more inertia ("memory") on abnormal returns than at firm level)

The next sections apply this methodology to a specific dataset.

\section{Data, Measurements, and Statistical Pro- CEDURE}

\section{Sample}

We use data from Spanish firms belonging to all sectors of the economy. Our initial sample consists of 5,000 large Spanish firms, excluding financial and public companies. For each firm, financial data was collected for the 19952000 period. The dataset contains information about Return on Assets (ROA) and a 4-digit SIC code that identifies the industry membership. Our initial database contains 30,000 records, each of a single firm in a particular year between 1995 and 2000 .

Before the analysis, we screened the database in several ways. First, we eliminated 53 firms (318 records) that did not contain a SIC code designation. Secondly, we conducted a preliminary data analysis to identify outliers. We eliminated records outside 10 times the inter-quartile interval of ROA in any of the years considered. The screened data set includes 29,586 records of 4,931 firms in 342 4-digit SIC industries. 
As we do not focus on the corporate effect, we eliminate all diversified firms, that is, firms that appear in more than one industry in our dataset. In this (non-diversified) sample, the corporate effect is assumed to be absent (McGahan and Porter, 2002). As opposed to other studies (McGahan and Porter, 1997), we do not drop industries with only one firm (equivalent to monopoly), even though, of course, for this firm we cannot distinguish between industry and firm effects. Further, our database includes only large Spanish firms. Sales in the data base range from 8.8 thousands euros to 12.8 millions euros. Our data base captures a large portion of the Spanish economy, including all sectors (manufacturing, retail, wholesale trade, mining and agriculture, chemical business, transportation services, lodging and other services, entertainment) except for financial and government sectors. This broad classification of industry may dampen the industry effect, and can distort the firm effect as well (see McGahan and Porter, 1997, for comments on this issue).

Accounting return data was used in the analysis. As in previous studies (Schmalensee, 1985; Rumelt, 1991; Roquebert et al. 1996; Mauri and Michaels, 1998, McGahan and Porter, 1997), we use Return on Assets (ROA) as the measure of business performance. This variable was constructed by dividing the annual income (before extraordinary items) by the total assets. ROA was measured at yearly bases from 1995 to 2000. Subtracting ROA from its mean-year value we constructed the observed variable $Y_{i t j}$, where $i, t$ and $j$ denoted firm, time and industry, respectively.

\section{Estimation}

The model was fitted using structural equation model (SEM) methodology. SEM permits a suitable approximation for most research designs for longitudinal data, as we can easily formulate relationships between latent variables, rather than directly between their fallible measures. In fact, within SEM, permanent and temporary components are modelled as latent factors, it being easy to evaluate the portion of the total variance accounted by the different latent variables. Standard software can be used for fitting SEM models. In our application, however, given the non-linear restrictions of the variance of the initial conditions (associated to the stationary assumption), we used LISREL (Jöreskog, and Sörbom, 1996) that allows such contraints. For the two-level analysis, we found Mplus (Muthén and Muthén, 1998) to be the most convenient software. We make explicit the fitting functions used for the two-level analysis in Appendix A. 


\section{RESUlTS}

We first present a preliminary analysis of the data. Subsequent sub-sections discuss the model fit, and the decomposition of variance of abnormal returns between permanent, temporary, and the unexplained firm-year term.

\section{Preliminary analysis}

To assess the suitability of the proposed model, and the stationarity assumption in particular, we first inspected the evolution of ROA across the years, for each firm. Figure 2 shows the evolution of ROA for a sample of firms. This graph, does not reveal a substantial and serious upward or downward trend. The variance of ROA is also stable over time, since there is no observable change in dispersion of ROA.It seems therefore reasonable to assume that ROA follows a stationary process over time, as assumed by our model.

Insert Figure 2 about here

Figure 3 shows a matrix-plot of ROA and its correlations. The autocorrelations of adjacent measures of ROA are hughe. This suggests either strong autoregressive factors or stable individual differences. Only by partitioning the variance is it possible to identify the origin of this pattern of autocorrelation. Table 2 shows the means, standard deviations and correlations of the variable ROA across the years.

Insert Table 2 about here

Insert Figure 3 about here

\section{Estimation results}

The firm-level model in Figure 1 was fitted first. In the fit of the initially posed model, we found a discrepancy with the observed moments, as indicated by a significant chi-square goodness-of-fit value of $\chi_{12}^{2}=33.42$, $p \leq 0.05$. To improve the fit, we released the equality constraint of the disturbance terms for the temporary component in 1998 (in Figure 1, the variance of $D_{4}$ ). Thus, the variance explained by the temporary component is different 
from the other years too, and consequently the proportion of variance of ROA explained by the model is not the same as in the other years. The adjusted model now fits the data well, as shown by a chi-square goodness of fit test of $\chi_{11}^{2}=17.45$, with 10 degrees of freedom, $p$-value $=0.05$. Such a significant difference in the variance for the disturbance term of that year can in fact be justified a posteriori by the exceptional atypical economic circumstances occurring that year. The variance of the non-constrained disturbance term was 28.14 (1.26) greater than the constrained disturbance term, as shown in Table 3.

Parameter estimates with standard errors are shown in Table 3 . The variances of the transitory and permanent components are statistically significant, with the estimated autoregressive coefficient $\hat{\beta}=0.72$. This is significantly different than zero. These results assert the presence of a significant a permanent component of abnormal return, and a significant inertia effect of the transitory component. The variance of the disturbance term is also found to be statistically significant.

Insert Table 3 about here

These estimates lead to the variance decomposition shown in Table 4, where the variance of ROA is decomposed in permanent, temporary and firm-year unexplained components. Results are expressed as a percentage of the total variance of the abnormal returns (ROA). The temporary component ranges from 65.05 to 55.90 percent, it is the largest in all years. The average amount of variance accounted for by the permanent component is approximately $26 \%$. Thus the differences among firms are partly transitory, but a percentage of this variance is permanent, i.e. firms' differences that do not vanish over time.

Insert Table 4 about here

\section{Estimation results for the two-level model}

As discussed above, to provide more insight into the nature of the differences between firms, we distinguished contributions to abnormal returns at firm and industry levels. We fit a two-level model with one common parameter, the autoregressive coefficient $\beta$. The chi-square goodness-of-fit when fitting the two-level model with the autocorrelation coefficient $\beta$ restricted to being equal across the two levels, is $32.727(\mathrm{df}=31)$, which indicates an 
extremely good fit. Table 5 shows the parameter estimates with standard errors. The variance of the permanent component is statistically significant both at firm and industry levels. This means that permanent differences in profit rates exist simultaneously on two levels, firm and industry. The estimates of the variances of the industry- and firm-permanent components are 13.881 and 3.197, respectively, suggesting that permanent differences are about four times greater within industries than across industries.

Table 5 shows that the variance of the firm transitory component (50.464) is much greater than the industry transitory component (4.062). These results mean that short-run rents rises primarily on a firm level. Finally, the

autoregressive coefficient is estimated as $\hat{\beta}=0.744$, with a standard error that makes it to deviate significantly from both 0 and 1 . This means that profits decay toward the sample mean (i.e., the equilibrium level) at firm and industry levels. The hypothesis of equality of industry and firm autoregressive parameters (i.e., the same value at firm and industry level of the autoregressive parameter) is supported by the data.

Insert Table 5 about here

With these parameter estimates, we compute in Table 6 the proportion of variance of abnormal returns due to industry permanent, firm permanent, industry temporary and firm temporary components. Results are expressed as a percentage of the total variance of temporary and permanent components (that is, we excluded the unexplained firm-year component $U$ from the total variance). These results show that the permanent component at firm level $(81.25 \%)$ accounts for the greater part of the permanent variance; in the same way, temporary component at firm level, $92.55 \%$, accounts for the greater part of the transitory variance. Table 6 also shows that within-industry variance is greater that variance across industries. This is in accordance with results obtained in previous works (e.g. Rumelt, 1991; Roquebert et al., 1996; McGahan and Porter, 1997).

Insert Table 6 about here

\section{Discussion}

The present study provides a model suitable for studying the evolution of abnormal returns by means of a two-way variance decomposition of the abnormal return variable at firm and industry levels, and at permanent and 
temporary components. The application of the model to a Spanish sample of firms shows that there are permanent and temporary differences between profit rates, both at industry and firm levels, and that permanent and temporary differences are greater at firm than at industry level. These results support the main conclusions of previous research on sources of firm profit differences that concludes that firm effects are greater than industry effects in explaining profit firm differences. Our results also support the main conclusions of the persistence of profit line of research, that abnormal returns do not converge completely towards the sample mean and that some profit differences persist over time and follow an AR(1) process.

But our analysis differs from previous studies on the methodology adopted. Our two-level dynamic panel data model allows us to evaluate, in a single analysis, the relative importance of the permanent and transitory differences in abnormal returns, as well as the relative contributions of firms and industries to the variation of abnormal returns. This unified analysis integrates earlier evidence about the static and dynamic properties of abnormal returns, and disentangles the influences of industry structure and firm-specific efficiencies in the genesis of the permanent and temporary components of abnormal returns.

\section{Convergence of abnormal profits}

The analysis yields statistically significant variances of the permanent and temporary components of abnormal returns, both at the industry and firm level; the hypothesis of full convergence (Hypothesis 0) is not supported by our dataset. Industry- and firm-specific rents persist over time, and returns do not converge completely to a long-run equilibrium profit rate. Firms that are more (less) profitable at the beginning of the period remain more (less) profitable at the end, confirming, our Hypothesis 3. These result can be explained by the restricted effectiveness of the competition process due to the existence of entry (Bain, 1956) or mobility barriers (Caves and Porter, 1977). But this does not necessarily mean that these abnormal returns were due to the existence of monopoly rents as classical industrial organization argues. These facts also confirm the Resource-Based view (Wernerfelt, 1984; Rumelt, 1984; Peteraf, 1993) and Efficiency- or Shumpeterian-view (Demsetz, 1973; Peltzman, 1977, Roberts, 1999; Jacobson and Hansen, 2001). In the first case, firms can sustain differences by developing "isolation mechanisms" that preclude the process of imitation (Rumelt, 1984), or this may be a consequence of the different endowment of resources on which the competitive advantage of the firm was based (Williams, 1992). From the Efficiency or Schumpeterian point of view, abnormal returns may be regarded as su- 
perior productivity, above-average growth in sales (Demsetz, 1973) or firm's differential ability of product innovation (Roberts, 1999, 2001).

The importance of these alternative explanations depends on the sources of abnormal returns. If permanent and temporary differences arise mainly at the industry level, barriers to entry may be a plausible explanation, and rents earned by successful firms can be regarded as monopoly rents. On the other hand, if differences arise principally at the firm level, differences reflect heterogeneity between firms due to the different endowment of resources or superior efficiency of more profitable firms.

\section{Industry vs. firm effects}

Results in Table 6 show that permanent and temporary abnormal returns arise mainly at firm level. Within-industry differences are greater than across-industry differences and temporary differences are greater than permanent differences both on industry and firm levels. These results are consistent with those obtained by previous research using classical variance and covariance component techniques, but differ regarding the relative magnitude of the industry and firm effects.

In our results, firm effects are about nine times greater than industry effects, a difference greater than obtained in previous research. But these results are not directly comparable. A way to reconcile these findings is by acknowledging that in the results obtained, error term is smaller than in classical covariance analysis techniques. Moreover, both industry and firm

effects include the transient effects that are not usually contemplated. Taking these factors into account, our estimates are more in agreement with those obtained by previous research.

\section{Persistence of industry and firm abnormal returns.}

A complementary relevant question raised in this paper is the persistence of abnormal returns. The model proposes that short-run rents follow a firstorder autoregressive process. The estimated autoregressive coefficient $(\hat{\beta}=$ $0.744)$ is significantly less than one. This means that short-run rents converge to the sample mean, but the process of convergence is slow, and transient differences do not disappear immediately.

These results support the profit persistence hypothesis. Our findings are consistent with previous studies, such as those by Mueller $(1977,1986)$, Jacobsen (1988) and McGahan and Porter (1997), which, using time series methodology, demonstrated that profits do not converge quickly to the level of equilibrium. 
The results obtained provide additional insights into the process of convergence. The stationary assumption suggests the percentage of variance attributable to permanent (temporary) component was stable over time. This means that the capability of firms (and industries) to sustain their competitive advantages remains constant over the period studied, i.e. there is no variation in the degree of sustainability of the competitive advantage over time. This results agree with those obtained by McNamara, Vaaler, and Devers (2003) in their search for evidence of increasing hypercompetition in markets, where they do not observe an increased trend in the instability of business performance and in the durability of abnormal business returns, as the hypercompetition view (D'Aveni, 1994) emphasizes.

In summary, these results suggest that there are permanent and transitory differences in abnormal returns on industry and firm levels, although these differences are greater within industries than across industries. Moreover, the speed of convergence of temporary differences is equal between industries and between firms. Here we distinguished only two levels; the same approach, however, would apply in the case where we have more than two levels, e.g. firm, corporation and industry.

\section{References}

Anderson T, Hsiao C. 1982. Estimation of dynamic models using panel data. Journal of Econometrics 18: 47-82.

Bain J. 1956. Barriers to new competition. Harvard University Press: Cambridge, MA.

Benston G. 1985. The validity of profits-structure studies with particular reference to the FTC's line of Business data. American Economic Review $75(1)$ : 37-67.

Brush TH, Bromiley P. 1999. The relative influence of industry and corporation on business segment performance: An alternative estimate. Strategic Management Journal 20: 519-547.

Carroll GR. 1993. A sociological view on why firms differ. Strategic Management Journal 14: 237-249.

Caves RE. 1980. Industrial organization, corporate strategy, and structure: a survey. Journal of Economic Literature 18(1): 64-92.

Caves R, Porter ME. 1977. From entry barriers to mobility barriers. Quarterly Journal of Economics 91: 421-441.

Coate MB. 1989. The dynamics of price-cost margins in concentrated industries. Applied Economics. 21: 261-272.

Coate MB. 1991. The effect of dynamic competition on price-cost margins. Applied Economics 23: 1065-1076. 
Cubbin J, Geroski P. 1987. The convergence of profits in the long run: Interfirm and inter-industry comparisons. Journal of Industrial Economics 35(4): 427-442.

Cubbin J, Geroski PA. 1990. The persistence of profits in the United Kingdom. In The Dynamics of Company Profits: An International Comparison, D. Mueller (ed). Cambridge University Press: Cambridge; 147-167.

D'Aveni RA. 1994. Hypercompetition. Free Press: NY.

Demsetz H. 1973. Industry structure, market rivalry, and public policy. Journal of Law and Economics 16: 1-10.

Demsetz H. 1979. Accounting for advertising as a barrier to entry. Journal of Business 59, July: 345-360.

Fisher FM, McGowan JJ. 1983. On the misuse of accounting rates of return to infer monopoly profits. American Economic Review 73(1): 82-97.

Geroski PA, Jacquemin A. 1988. The persistence of profits: A European comparison. The Economic Journal 98, June: 375-389.

Geroski PA. 1990. Modeling persistent profitability. In The Dynamics of Company Profits: An International Comparison, Mueller DC. (ed). Cambridge University Press: Cambridge; 15-34.

Jacobson R. 1988. The persistence of abnormal returns. Strategic Management Journal 9: 415-430.

Jacobson R, Hansen G. 2001. Modeling the competitive process. Managerial and Decision Economics 22: 251-263.

Jöreskog K, Sörbom D. 1996. LISREL 8: User'S Reference Guide. Scientific Software: Chicago, IL.

Kenny D, Zautra A. 1985. The trait-state-error model for multiwave data. Journal of Consulting and Clinical Psychology 63(1): 52-59.

Kenny D, Zautra A. 2001. Trait-state models for longitudinal data. In New methods for the analysis of change Collins LM, and Sayer AG (eds). American Psychological Association: Washington; 243-263.

Lippman S, Rumelt RP. 1982. Uncertain imitability: an analysis of interfirm differences in efficiency under competition. Bell Journal of Economics 13: $418-438$.

Mahoney JT, Pandian J. 1992. The resource-based view within the conversation of strategic management. Strategic Management Journal 13: 363-380.

Maruyama N, Odagiri H. 2002. Does the 'persistence of profits' persist?: A study of company profits in Japan, 1964-97. International Journal of Industrial Organization 20: 1513-1533.

Mauri AJ, Michaels MP. 1998. Firm and industry effects within strategic management: An empirical examination. Strategic Management Journal 19: 211-219. 
McGahan AM, Porter ME. 1997. How much does industry matter, really? Strategic Management Journal 18: 15-30.

McGahan AM, Porter ME. 1999. The persistence of shocks to profitability. Review of Economics and Statistics 81(1): 143-153.

McGahan AM, Porter ME. 2002. What do we know about variance in accounting profitability. Management Science 48(7): 834-851.

McNamara G, Vaaler PM, Devers C. 2003. Same as it ever was: The search for evidence of increasing hypercompetition. Strategic Management Journal 24: 261-278.

Mueller DC. 1977. The persistence of Profits above the norm. Economica 44, November: 369-380.

Mueller DC. 1986. Profits in the long run. Cambridge University Press: Cambridge.

Mueller DC. 1990. Profits and the process of competition. In The Dynamics of Company Profits: An International Comparison, Mueller D. (ed). Cambridge University Press: Cambridge; 1-14.

Mueller DC, Raunig B. 1999. Heterogeneities within industries and StructurePerformance models. Review of Industrial Organization 15: 303-320.

Muthén BO. 1994. Multilevel Covariance Structure Analysis. Sociological Methos \& Research 22: 376-398.

Muthén BO, Muthén LK. 1998. Mplus User's Guide. Muthén and Muthén: Los Angeles, CA.

Muthén BO, Satorra A. 1995. Complex Sample Data in Structural Equation Modeling. Sociological Methodology 25: 267-316.

Nesselroade JR. 1991. Interindividual differences in intraindividual change. In Best Methods for the Analysis of Change, Collins LM., and Horn JL. (eds). American Psychological Association: Washington; 92-105.

Odagiri H. Yamawaki H. 1986. A study of company profit-rate time series, Japan and the United States. International Journal of Industrial Organization 4: 1-23.

Peltzman S. 1977. The gains and losses from industrial concentration. Journal of Law and Economics October: 229-263.

Peteraf MA. 1993. The cornerstones of competitive advantage: A resourcebased view. Strategic Management Journal 14: 179-191.

Porter ME. 1981. The contributions of industrial organization to strategic management. Academy of Management Review 6: 609-620.

Powell TC. 1996. How much does industry matter? An alternative empirical test. Strategic Management Journal 17: 323-334.

Roberts PW. 1999. Product innovation, product-market competition and persistent profitability in the U.S. pharmaceutical industry. Strategic Management Journal 20: 655-670. 
Roberts PW. 2001. Innovation and firm-level persistent profitability: A Schumpeterian framework. Managerial and Decision Economics 22: 239250.

Roquebert JA, Phillips RL, Westfall PA. 1996. Markets vs. management: What 'drives profitability?'. Strategic Management Journal 17: 653-664.

Rumelt RP. 1984. Toward a strategic theory of the firm. In Competitive Strategic Management, Lamb R. (ed). Prentice Hal: Englewood Cliffs, NJ; 556-570.

Rumelt RP. 1987. Theory, strategy and entrepreneurship. In The Competitive Challenge, Teece D. (ed). Ballinger, Cambridge, MA; 137-158.

Rumelt RP. 1991. How much does industry matter? Strategic Management Journal 12: 167-185.

Schmalensee RP. 1985. Do markets differ much? American Economic Review 75(3): 341-351.

Satorra A. 1993. Asymptotic robust inferences in multiple-group analysis of augmented-moment structures. In Multivariate Analysis: Future Directions 2, Cuadras CM. and Rao CR. (ed). Amsterdam: Elsevier; 211-229.

Satorra A. 2002. Asymptotic robustness in multiple group linear-latent variale models. Econometric Theory 18: 297-312.

Schwalbach J, Grasshoff U, Mahmood T. 1989. The dynamics of corporate profits. European Economic Review 33: 1625-1639.

Waring G. 1996. Industry differences in the persistence of firm-specific returns. American Economic Review 86(5): 1253-1265.

Wernerfelt B. 1984. A resource-based view of the firm. Strategic Management Journal 5: 171-180.

Wernerfelt B. Montgomery CA. 1988. Tobin's q and the importance of focus in firm performance. American Economic Review 78(1): 246-250.

Williams J. 1992. How sustainable is your competitive advantage? California Management Review, Spring: 29-51. 


\section{APPENDIX A: LIKELIHOOD FUNCTION FOR THE TWO- LEVEL MODEL}

For the sake of completeness, this appendix provides the likelihood expressions for the two-level data, as well as the expression of the (pseudo) likelihood fitting function used in obtaining the (MUML) estimates reported in the paper. For SEM analysis of single-level multiple-group data, the reader is referred elsewhere (e.g., Satorra, 1993, 2002).

Consider a $p$-variate (centered) vector $z_{i g}$ of observed variables and the following two-level data set-up:

$$
z_{i g}=v_{g}+w_{i g}, \quad i=1, \ldots n_{g}, g=1,2, \ldots G
$$

where $v$ and $w$ are respectively first- and second-level random components, such that $\mathcal{E} v_{g}=\mathcal{E} w_{i g}=0$, with the $v_{g}$ 's being independent of the $w_{i g}$ 's. The random components $v$ and $w$ are assumed to have finite variance matrices $\Sigma_{v}$ and $\Sigma_{w}$ respectively, $\mathcal{E}($.$) denoting expected value. In the set-up of our paper,$ the vector $z$ corresponds to the vector of observed abnormal returns for firm $i$ th of industry $g$, and $v$ and $w$ correspond respectively to the industry- and firm-level contributions of abnormal returns. For a given model, $\Sigma_{v}$ and $\Sigma_{w}$ are specific functions $\Sigma_{v}=\Sigma_{v}(\theta)$ and $\Sigma_{w}=\Sigma_{w}(\theta)$ of a common vector $\theta$ of parameters.

An affine transformation of the log-likelihood is (see Muthén and Satorra, 1995, p. 292-203)

$$
\begin{gathered}
f:=(n-G)\left\{\operatorname{tr} \Sigma_{1}^{-1} S_{W}+\ln \left|\Sigma_{1}\right|\right\}+ \\
+\sum_{g=1}^{G}\left\{\operatorname{tr}\left(\Sigma_{2}+n_{g}^{-1} \Sigma_{1}\right)^{-1} z_{. g} z_{. g}^{\prime}+\ln \left|\Sigma_{2}+n_{g}^{-1} \Sigma_{1}\right|\right\}
\end{gathered}
$$

where

$$
S_{W}:=(n-G)^{-1} \sum_{g=1}^{G} \sum_{i=1}^{n_{g}}\left(z_{i g}-z_{. g}\right)\left(z_{i g}-z_{. g}\right)^{\prime}
$$

is the so-called variances and covariance matrix " within" and $z_{. g}:=n_{g}^{-1} \sum_{g=1}^{G} z_{i g}$ is the mean vector of the $g$ th group. Since $\Sigma_{v}$ and $\Sigma_{w}$ are functions of $\theta$, a function $f=f(\theta)$ is obtained. Minimization of $f=f(\theta)$ will thus lead to maximum likelihood estimation.

In the balanced case, i.e. when $n_{g}=n$. for all $g$, the likelihood function has a two-group moment structure form,

$$
\begin{gathered}
f=(n-G)\left\{\operatorname{tr} \Sigma_{w}^{-1} S_{w}+\ln \left|\Sigma_{w}\right|\right\} \\
+G\left\{\operatorname{tr}\left(\Sigma_{v}+n .{ }^{-1} \Sigma_{w}\right)^{-1} S_{b}+\ln \left|\Sigma_{v}+n .{ }^{-1} \Sigma_{w}\right|\right\}
\end{gathered}
$$


where

$$
S_{w}:=(n-G)^{-1} \sum_{g=1}^{G} \sum_{i=1}^{n_{g}}\left(z_{i g}-z_{. g}\right)\left(z_{i g}-z_{. g}\right)^{\prime}
$$

and

$$
S_{b}:=G^{-1} \sum_{g=1}^{G} z_{. g} z_{. g}{ }^{\prime},
$$

are the "within" and "between" sample moment matrices. Equivalently, instead of maximizing $f$, we could just minimize the fitting function

$$
\begin{gathered}
F:=(n-G)\left\{\operatorname{tr} \Sigma_{w}^{-1} S_{w}+\ln \left|\Sigma_{w}\right|-\ln \left|S_{w}\right|-p\right\} \\
+G\left\{\operatorname{tr}\left(\Sigma_{v}+n .^{-1} \Sigma_{w}\right)^{-1} S_{b}+\ln \left|\Sigma_{v}+n .{ }^{-1} \Sigma_{w}\right|-\ln \left|S_{v}\right|-p\right\},
\end{gathered}
$$

where some offset terms ensure that the minimum corresponds to the usual chi-square goodness of fit test statistic.

The fitting function $F$ with $c=\frac{n^{2}-\sum_{g} n_{g}^{2}}{n(G-1)}$ instead of $n$. in the case of unbalanced data, is the fitting function minimized in the MUML approach of Muthén (1994). Clearly, in the case of balanced data, $c=n_{\text {.; }}$ so, for balanced data, MUML coincides with exact ML estimation. (see Muthén and Satorra, 1995, p. 292-203) For unbalanced data, MUML provides still consistent estimates of the parameters of the model. Experience with the MULM estimates of the Muthén (1994) approach to multilevel data shows that, even in the case of unbalanced data, the estimates, standard errors, and chi-square values are very close to the true full ML approach. This is what we experience with our data, when we directly minimized the ML function described above. We decided to keep the results given by the MULM, given the quality of such estimates, and the easy access by Mplus, or via the two-group analysis available in other SEM software such as LISREL. The appendix below gives the LISREL and Mplus code that produced the results reported in the paper. 


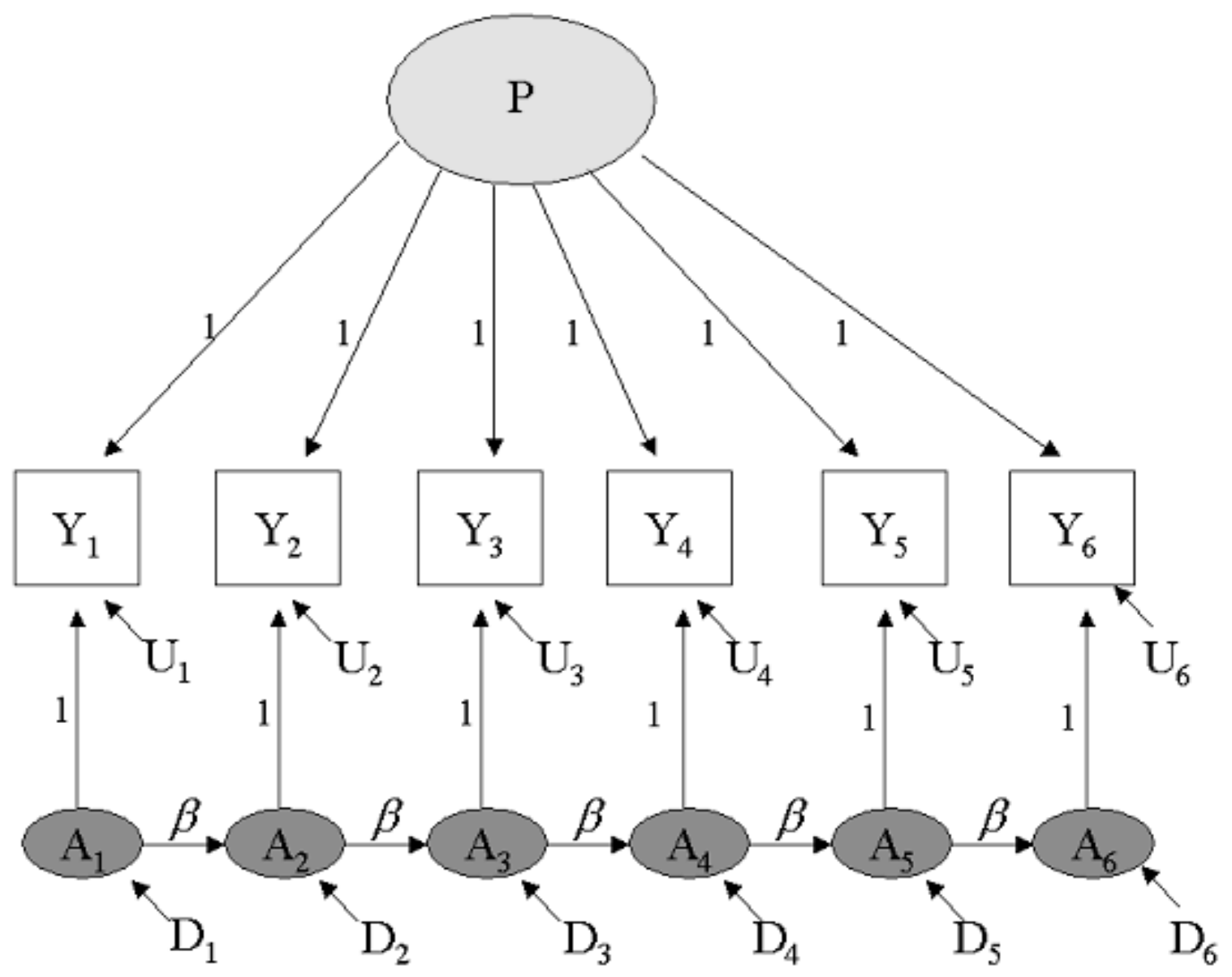

Figure 1: Path-diagram representation of the model 


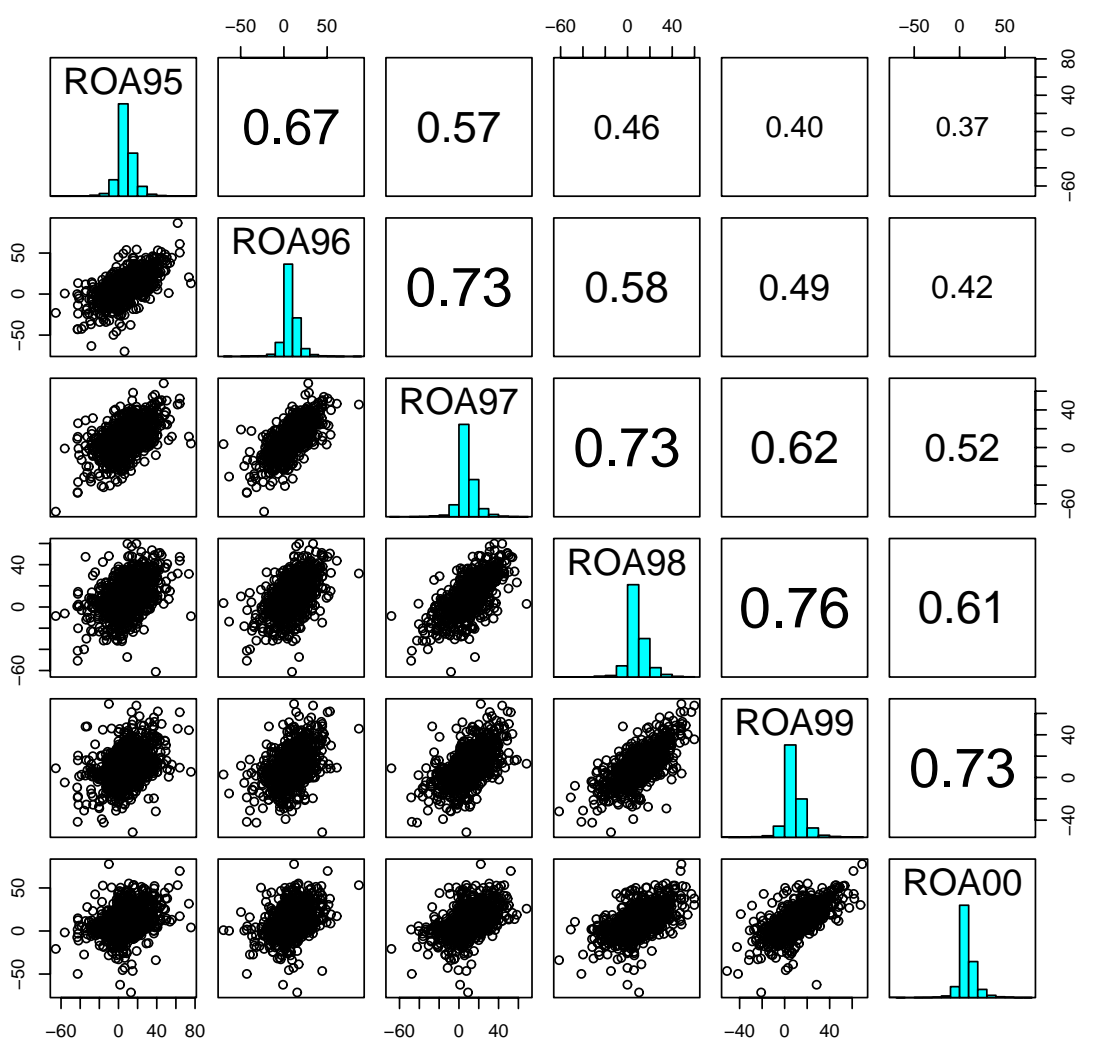

Figure 2: Matrix-plot and correlations of ROA for years $1995-2000$ 


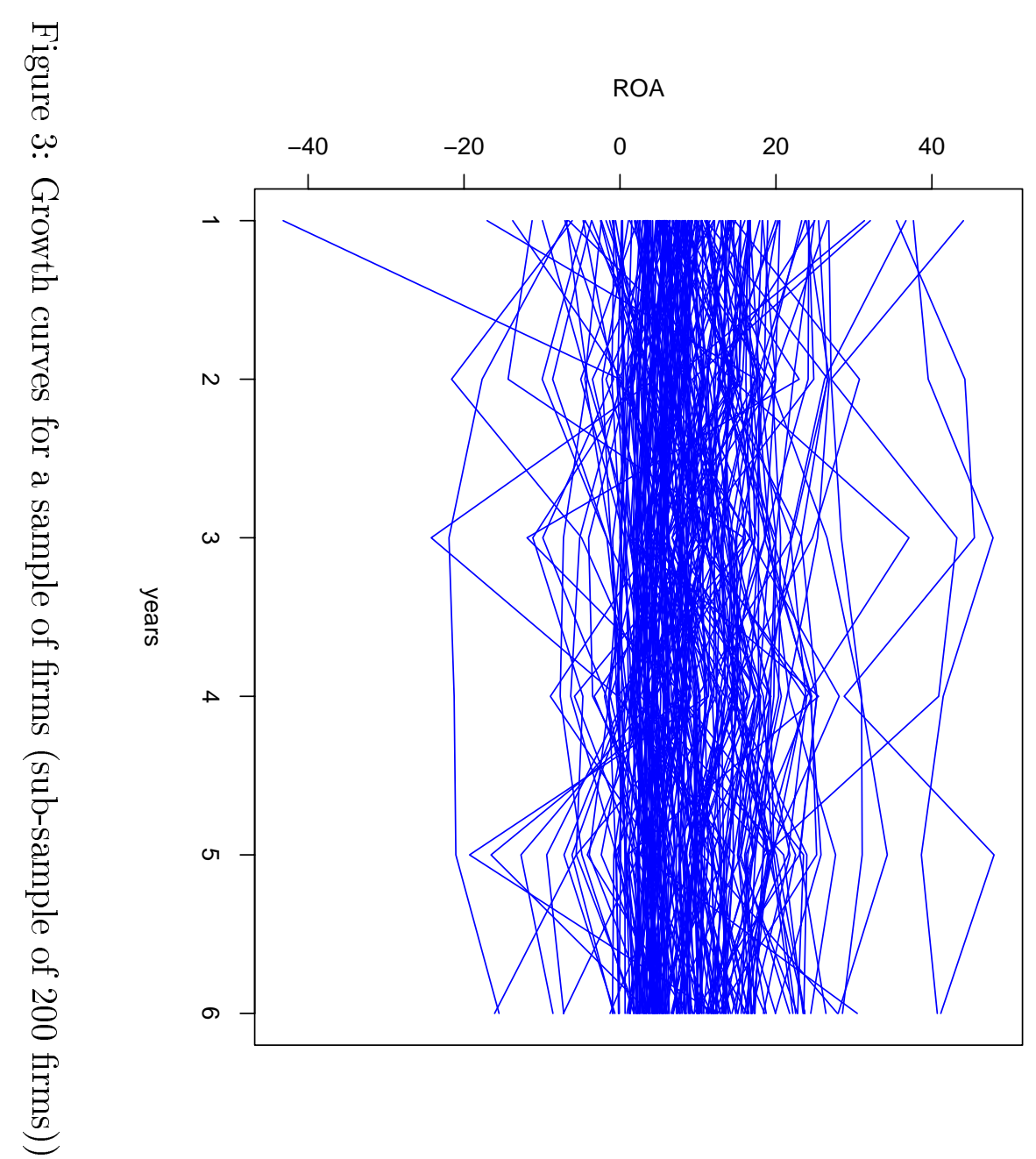


Table 1: Persistence of abnormal returns

\begin{tabular}{|c|c|c|c|c|}
\hline \multirow[b]{2}{*}{ Hypothesis } & \multicolumn{3}{|c|}{ Variance components } & \multirow[b]{2}{*}{ abnormal returns } \\
\hline & $\operatorname{Var} P$ & $\operatorname{Var} A$ & $\operatorname{Var} U$ & \\
\hline H0: & & & * & no ${ }^{1}$ \\
\hline H1: & $*$ & & * & yes \\
\hline H2: & & $*$ & * & yes \\
\hline H3: & $*$ & $*$ & $*$ & yes \\
\hline
\end{tabular}

* asterisk indicates non-zero variance

1 "yes" and "no" indicates respectively the presence or not of abnormal returns 
Table 2: Means, sd and correlations

\begin{tabular}{lrrrrrrrr}
\hline & Mean & SD & 1 & 2 & 3 & 3 & 5 & 6 \\
\hline 1. ROA 95 & 7.745 & 9.396 & 1.000 & & & & & \\
2. ROA 96 & 7.558 & 8.886 & 0.671 & 1.000 & & & & \\
3. ROA 97 & 7.739 & 8.852 & 0.567 & 0.727 & 1.000 & & & \\
4. ROA 98 & 8.037 & 8.928 & 0.460 & 0.576 & 0.727 & 1.000 & & \\
5. ROA 99 & 8.134 & 8.868 & 0.403 & 0.489 & 0.616 & 0.758 & 1.000 & \\
6. ROA 00 & 7.982 & 8.960 & 0.365 & 0.420 & 0.515 & 0.605 & 0.727 & 1.000 \\
\hline
\end{tabular}


Table 3: Parameter estimates and standard errors

\begin{tabular}{lrr}
\hline Parameter & Estimate & se \\
\hline $\operatorname{Var}(\mathrm{P})$ & 21.04 & 2.51 \\
$\beta$ & 0.72 & 0.02 \\
$\operatorname{Var}(\mathrm{D})$ & 24.06 & 0.92 \\
$\operatorname{Var}(\mathrm{A})$ & 49.58 & 1.32 \\
\hline
\end{tabular}


Table 4: Decomposition of variance of ROA (in \%)

\begin{tabular}{lrrr}
\hline Variable & Temporary & Permanent & Error \\
\hline ROA95 & 55.90 & 23.72 & 20.37 \\
ROA96 & 62.47 & 26.31 & 11.22 \\
ROA97 & 65.05 & 27.40 & 7.55 \\
ROA98 & 69.09 & 24.88 & 6.03 \\
ROA99 & 65.27 & 27.49 & 7.24 \\
\hline
\end{tabular}


Table 5: Parameter estimates with se of the two-level model

\begin{tabular}{lrrrr}
\hline Parameter & Estimate & se & Estimate & se \\
\hline $\operatorname{Var}(\mathrm{P})$ & 13.881 & 3.393 & 3.197 & 0.701 \\
$\beta$ & 0.744 & 0.026 & 0.744 & 0.026 \\
$\operatorname{Var}(\mathrm{D})$ & 22.515 & 01.600 & 1.812 & 0.328 \\
$\operatorname{Var}(\mathrm{A})$ & 50.464 & 4.58 & 4.062 & 2.40 \\
\hline
\end{tabular}


Table 6: Industry and firm variance decomposition of ROA

\begin{tabular}{lrrr}
\hline Components & Permanent & Temporary & Marginal \\
\hline & & & \\
Firm & $13.88(19.38 \%)$ & $50.46(70.48 \%)$ & $64.34(89.86 \%)$ \\
Industry & $3.20(4.46 \%)$ & $4.06(5.67 \%)$ & $7.26(10.14 \%)$ \\
Marginal & $17.08(23.85 \%)$ & $54.53(76.15 \%)$ & 1 \\
\hline
\end{tabular}

